\title{
Association of High Sensitive C - Reactive Protein with Severity of the Left Ventricular Systolic Dysfunction in Acute Anterior ST Elevation Myocardial Infarction
}

\author{
Rahman $\mathrm{A}^{1 *}$, Chowdhury $\mathrm{AW}^{2}$, Khan $\mathrm{HILR}^{2}$, Sabah $\mathrm{KMN}^{2}$, Amin $\mathrm{MG}^{2}$, Azad SMAA ${ }^{3}$ \\ ${ }^{1}$ Department of Cardiology, BIRDEM General Hospital, Dhaka, Bangladesh \\ ${ }^{2}$ Department of Cardiology, Dhaka Medical College Hospital, Dhaka, Bangladesh \\ ${ }^{3}$ Popular Hospital, Narayangonj, Bangladesh
}

\begin{abstract}
High Sensitive C-reactive protein (hs- CRP) is an established risk marker in coronary artery disease. It is a marker of inflammation activated early after Acute Myocardial Infarction (AMI) and its quantity depends upon extent of myocardial damage. Release of inflammatory marker occur after acute myocardial infarction leading to cardiac remodeling which clinically manifests as Heart failure (HF). Heart failure is a common complication after acute anterior myocardial infarction (AMI). The prevalence of post-infarct Left Ventricular Systolic Dysfunction (LVSD) ranges from 27 to $60 \%$ and half of patients having early postinfarct LVSD subsequently develop chronic heart failure. The purpose of this study is to show association between hs-CRP with LVSD in AMI and early detection of HF. This was a cross-sectional analytical study in which hs-CRP was done among all the study subjects between 24-48 hours after onset of AMI. The study population was categorized into groups I, II, II according to the lowest to highest hs-CRP level. Transthoracic echocardiography was done between 24-48 hours of anterior ST Elevation Myocardial Infarction (STEMI). Then LVSD was assessed between those three groups and searched for association. Severely reduced ejection fraction (EF) was found in patients of group III (highest hs-CRP tertile) only. Severe and moderately reduced EF and FS was found significantly more in group III and II than group I (mid and lowest hs-CRP tertile) $(p<0.001)$. High level of hs-CRP in patient of acute anterior STEMI patients was associated with moderate to severe reduction in EF and Fractional Shortening (FS). So hs- CRP may be a prognostic marker in acute anterior STEMI complicating LVSD and early management would improved the short and long term prognosis.
\end{abstract}

Keywords: High Sensitive C-reactive protein (hs- CRP), Left Ventricular Systolic Dysfunction (LVSD)

\section{Introduction}

Heart failure (HF) is a common complication after acute anterior myocardial infarction (AMI) even with the improved therapeutic management. ${ }^{1}$ Among acute myocardial infarction incidence of $\mathrm{HF}$ is more in STEMI patients than in patients with NSTEMI. ${ }^{2}$ Following myocardial infarction left ventricular systolic dysfunction (LVSD) has been identified as a powerful marker of poor prognosis. Its occurrence is associated with an increased risk of cardiac death, re-infarction and rehospitalization. ${ }^{3}$ The prevalence of post-infarct LVSD ranges from 27 to $60 \% .{ }^{4,5}$ Furthermore, half of patients diagnosed early post-infarct LVSD subsequently develop chronic heart failure. $\mathrm{HF}$ occurs early as a complication of myocardial tissue

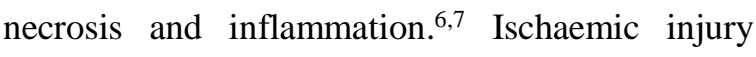
promotes myocardial inflammation, and pro- inflammatory cytokines that stimulate synthesis of C-reactive protein (CRP) leading to cardiac remodeling (refers to anatomical and physiological alteration of heart after myocardial injury) which clinically manifests as $\mathrm{HF}^{8}$ Although CRP is a marker of inflammation activated early after AMI and it is associated with HF. ${ }^{9-13}$ The overall effects of inflammatory cytokines can be favorable or unfavorable. Healing of myocardial injury and restoration of function is a favorable effect, but leftventricular (LV) re-modelling and myocardial failure is the most unfavorable one. An increase in hs-CRP plasma concentration in the course of acute MI begins in the first hours following the onset of symptoms, peaks approximately on day 2, and returns to its baseline value after a few weeks. ${ }^{14}$ Increased hs-CRP levels in MI have been associated with adverse clinical outcomes and larger 
infarctions as assessed by enzymatic assays. ${ }^{13,15}$ Assessment and inclusion of C-reactive protein combined with the GRACE risk score in ACS improves patient risk stratification. ${ }^{16}$ However, the link between hs-CRP and structural and functional cardiac alterations in STEMI patients warrants further investigation. Some studies showed increased CRP level is associated with heart failure and acute MI but there is limited data which showed association between hs-CRP with LV systolic dysfunction in AMI. This study was aimed to explore future direction for aggressive management, early intervention, future adverse risk assessment, regular post discharge follow-up and regular intensive medications in anterior-STEMI patients with LVSD and thus help in improving the short and long term prognosis of these patients.

\section{Materials and Methods}

A cross sectional analytical study was done in the Department of Cardiology, Dhaka Medical College Hospital, Dhaka during October, 2013 - September, 2014. The diagnosis of acute anterior STEMI was done by identifying characteristic ST segment elevation from $\mathrm{V}_{1}-\mathrm{V}_{6}$ plus either typical chest pain or elevated cardiac biomarkers. Among these patients, thrombolysed acute anterior STEMI were selected for echocardiography and further data collection and analysis. Old myocardial infarction/post PCI/post CABG, chronic heart failure, cardiomyopathy/ valvular heart disease, patient with LBBB, WPW syndrome, ventricular arrhythmia, advanced second degree and third degree conduction defect and ventricular electronic pacing were exluded. Other causes of ST segment elevation in ECG other than MI i.e. pericarditis, Prinzmetal angina, Brugada syndrome etc. Patient with poor echocardiographic window and severe co-morbid condition such as ESRD, cirrhosis of liver, malignancy, arthritis, or patient having any known chronic inflammatory disease were also excluded from the study.

Serum high sensitivity C-reactive protein was measured by latex-enhanced immune nephelometry on a Behring BN-Pro Spec Nephelometer (SIEMENS, USA) in the laboratories of the Department of Laboratory Medicine and Microbiology, BSMMU. hs-CRP was done among all the study subjects between 24-48 hours after onset of MI. The available hs-CRP level ranged from $12 \mathrm{mg} / \mathrm{L}$ to $114 \mathrm{mg} / \mathrm{L}$. The study population was categorized into three groups according to equal distribution of available hs-CRP level. The lowest hs-CRP group (hs-CRP=12-46 mg/L) was designated as group I, middle hs-CRP group (hs$\mathrm{CRP}=>46-80 \mathrm{mg} / \mathrm{L}$ ) was designated as group II and highest hs-CRP group (hs-CRP $=>80-114$ $\mathrm{mg} / \mathrm{L}$ ) was designated as group III.

Transthoracic echocardiography was done between 24 hours - 48 hours of anterior STEMI (using GE Vivid 7 echocardiography machine). Echocardiographic parameter of LV systolic function was measured by $2 \mathrm{D} \& \mathrm{M}$ - mode in parasternal short axis at papillary muscle level, parasternal long axis at the level of tip of the mitral valve and also by eye ball measurements. Then LVSD was assessed between those groups and searched for association between hs-CRP level and LVSD.

Ethical clearance was obtained from the Institutional Ethical Review Committee. Informed consent were taken from all the study subjects or from the legal guardians before enrolling them in the study. All the patients selected as study subjects were evaluated for demographic profile (age, sex), risk factors for coronary artery disease like diabetes, hypertension, dyslipidemia, smoking, obesity and family history of premature CAD. Baseline investigations e.g. ECG, troponin I, fasting lipid profile, fasting blood sugar (FBS) were done for each patient. All the information were properly noted in the preformed data collection sheet.

Data are presented as mean values $\pm \mathrm{SD}$, or percentage (\%). Means are compared by the Student $t$ test, and percentages are compared by Z-test of proportion. Chi-square test was done for qualitative variables. All statistical analyses were performed using the SPSS software 17 and $p \leq 0.05$ was considered significant.

In this study sample size was limited. It was conducted in a single tertiary care hospital which may not represent the general population. Long term follow up (after 6 month) was not done in this study.

\section{Results}

One hundred and thirty five patients with acute anterior STEMI who got thrombolysis in CCU were 
enrolled in the study to assess hs-CRP level in blood and LVSD by echocardiography. The study populations were categorized into group I, II and III according to equal distribution of available hs-CRP level (from lowest to highest).

The demographic and clinical variables of the study populations are summarized below (table I).

Table I: Baseline variables of study patients $(n=135)$

\begin{tabular}{|c|c|c|c|c|}
\hline $\begin{array}{c}\text { Demographic } \\
\text { Profile }\end{array}$ & $\begin{array}{c}\text { Group I } \\
\mathbf{n}_{1=81}\end{array}$ & $\begin{array}{c}\text { Group II } \\
\mathbf{n}_{\mathbf{2}}=\mathbf{3 0}\end{array}$ & $\begin{array}{c}\text { Group } \\
\text { III } \\
\mathbf{n}_{3=24}\end{array}$ & $p$ value \\
\hline Age in years & $\begin{array}{l}53.1 \pm 12.7 \\
\text { mean } \pm \text { SD }\end{array}$ & $\begin{array}{c}54.6 \pm 16 \\
\text { mean } \pm \text { SD }\end{array}$ & $\begin{array}{l}63.7 \pm 13.9 \\
\text { mean } \pm \text { SD }\end{array}$ & $\begin{array}{c}\text { Gr I Vs II= } \\
{ }^{\mathrm{a}} 0.594^{\mathrm{NS}} \\
\text { Gr I Vs } \\
\text { III }={ }^{\mathrm{a}} 0.001^{\mathrm{s}} \\
\text { Gr II Vs III= } \\
0.034^{\mathrm{s}}\end{array}$ \\
\hline $\begin{array}{l}\text { Gender } \\
\text { Male }\end{array}$ & $72(88.9 \%)$ & $27(90.0 \%)$ & $21(87.5 \%)$ & ${ }^{\mathrm{b}} 0.959^{\mathrm{NS}}$ \\
\hline Female & $9(11.1 \%)$ & $3(10.0 \%)$ & $3(12.5 \%)$ & \\
\hline Smoking & $51(63.0 \%)$ & $21(70.0 \%)$ & $21(87.5 \%)$ & ${ }^{\mathrm{b}} 0.073^{\mathrm{NS}}$ \\
\hline $\begin{array}{l}\text { Hypertension } \\
\text { Family history }\end{array}$ & $37(45.7 \%)$ & $18(60.0 \%)$ & $15(62.5 \%)$ & ${ }^{\mathrm{b}} 0.210^{\mathrm{NS}}$ \\
\hline $\begin{array}{l}\text { of premature } \\
\mathrm{CAD}\end{array}$ & $15(18.5 \%)$ & $3(10.0 \%)$ & $3(12.5 \%)$ & b $0.492^{\mathrm{NS}}$ \\
\hline $\begin{array}{l}\text { Diabetes } \\
\text { mellitus }\end{array}$ & $26(32.1 \%)$ & $4(13.3 \%)$ & $11(45.8 \%)$ & ${ }^{\mathrm{b}} 0.031^{\mathrm{s}}$ \\
\hline Dyslipidemia & $11(13.8 \%)$ & $6(20.0 \%)$ & $9(37.5 \%)$ & ${ }^{\mathrm{b}} 0.033^{\mathrm{s}}$ \\
\hline
\end{tabular}

The mean $( \pm \mathrm{SD})$ of EF of group I, II and III was $49.69( \pm 7.71), 39.50( \pm 6.42)$ and $30.41( \pm 2.22) \%$ respectively. The mean $( \pm \mathrm{SD})$ of FS of group I, II and III was 23.96( \pm 4.23$), 19.56( \pm 4.19)$ and $16.13( \pm 1.48) \%$ respectively. The mean $( \pm \mathrm{SD})$ of both EF and FS of group III was significantly less than group I $(p<0.001)$ and group II $(p<0.001)$. The mean $( \pm \mathrm{SD}) \mathrm{FS}$ of group II was significantly less than group I $(p<0.001)$. The mean $( \pm \mathrm{SD}) \mathrm{FS}$ of group II was significantly $(p<0.001)$ less than group I (table II).

Table II: Distribution of LV function variables of the study population $(\mathrm{n}=135)$

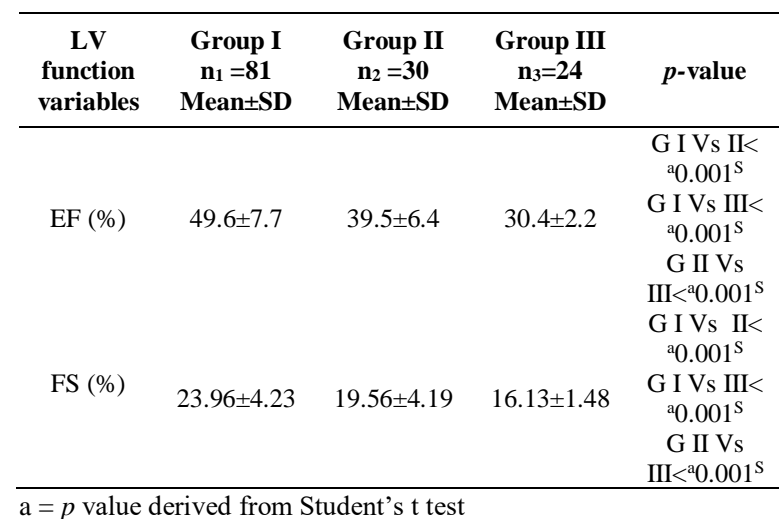

The severely reduced ejection fraction was found in $9(37.5 \%)$ patients of group III only (table III). Moderately reduced ejection fraction was found in $15(62.5 \%)$ patients of group III, $27(90.0 \%)$ patients of group II and 23 (28.4\%) patients of group I. Mildly reduced ejection fraction was found in $37(45.7 \%)$ patients of group I. Severe and moderately reduced ejection fraction was found significantly more in group III and II than group I $(p<0.001)$.

Table III: Distribution of ejection fraction and fractional shortening of the study population $(n=135)$

\begin{tabular}{|c|c|c|c|c|}
\hline LV variables & Group I $n_{1}=81$ & Group II $\mathbf{n}_{2}=\mathbf{3 0}$ & Group III $n_{3}=24$ & $p$ value \\
\hline EF & & & & \multirow{5}{*}{${ }^{b}<0.001^{s}$} \\
\hline Normal $(\geq 55 \%)$ & $21(25.9 \%)$ & $3(10.0 \%)$ & $0(0.0 \%)$ & \\
\hline Mildly reduced (45-54\%) & $37(45.7 \%)$ & $0(0.0 \%)$ & $0(0.0 \%)$ & \\
\hline Moderately reduced (30-44\%) & $23(28.4 \%)$ & $27(90.0 \%)$ & $15(62.5 \%)$ & \\
\hline Severely reduced $(<30 \%)$ & $0(0.0 \%)$ & $0(0.0 \%)$ & $9(37.5 \%)$ & \\
\hline \multicolumn{5}{|l|}{ FS } \\
\hline $\begin{array}{l}\text { Normal } \\
(27-45 \% \text { in women, } 25-43 \% \text { in men) }\end{array}$ & $18(22.2 \%)$ & $4(13.3 \%)$ & $0(0.0 \%)$ & \multirow{4}{*}{${ }^{\mathrm{b}}<0.001$} \\
\hline $\begin{array}{l}\text { Mildly reduced } \\
\text { ( } 22-26 \% \text { in women, } 20-24 \% \text { in men) }\end{array}$ & $36(44.4 \%)$ & $4(13.3 \%)$ & $0(0.0 \%)$ & \\
\hline $\begin{array}{l}\text { Moderately reduced } \\
(17-21 \text { in women, } 15-19 \% \text { in men) }\end{array}$ & $27(33.3 \%)$ & $19(63.3 \%)$ & $15(62.5 \%)$ & \\
\hline $\begin{array}{l}\text { Severely reduced } \\
(\leq 16 \text { in women, } \leq 14 \% \text { in men })\end{array}$ & $0(0.0 \%)$ & $3(10.0 \%)$ & $9(37.5 \%)$ & \\
\hline
\end{tabular}

The following table (table III) also demonstrates the severely reduced fractional shortening occurred in 9 $(37.5 \%)$ and $3(10.0 \%)$ in patients of group III and group II respectively. Moderately reduced fractional shortening occurred in 15 (62.5\%), 19
(63.3\%) and 27 (33.3\%) patients of group III, group II and group I respectively. Mildly reduced fractional shortening occurred in $4(13.3 \%)$ and 36 (44.4\%) patients of group II and group I respectively. Severe and moderately reduced 
fractional shortening was found significantly more in group III and II than group I $(p<0.001)$.

The linear regression analysis of hs-CRP with ejection fraction and fractional shortening (table IV). There was significant correlation of hs-CRP with ejection fraction $(\mathrm{r}=0.752, p<0.001)$ and fractional shortening $(\mathrm{r}=0.637, p<0.001)$.

Table IV: Linear regression analysis of hs-CRP with EF and FS $(\mathrm{n}=135)$

\begin{tabular}{lcccc}
\hline $\begin{array}{c}\text { LV function } \\
\text { variables }\end{array}$ & $\begin{array}{c}\text { Regression } \\
\text { coefficient (r) }\end{array}$ & $\begin{array}{c}\text { r } \\
\text { Square }\end{array}$ & $\begin{array}{c}\text { Adjusted } \\
\text { r Square }\end{array}$ & $\begin{array}{c}\boldsymbol{p} \text { - } \\
\text { value }\end{array}$ \\
\hline EF $(\%)$ & 0.752 & 0.565 & 0.548 & $<0.001$ \\
FS $(\%)$ & 0.637 & 0.406 & 0.401 & $<0.001$ \\
\hline
\end{tabular}

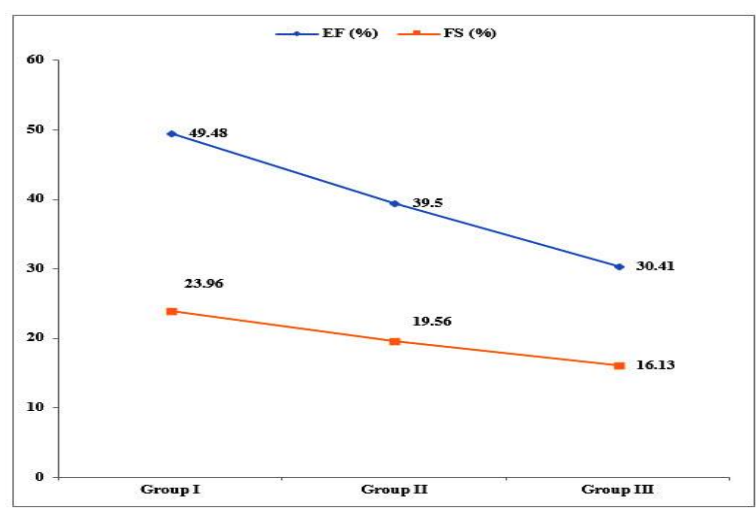

Figure 1: Association of EF (\%) \& FS (\%) with the level of hs-CRP

Group I= Lowest hs-CRP group (hs-CRP=12-46 mg/L)

Group II $=$ Middle hs-CRP group $(\mathrm{hs}-\mathrm{CRP}=>46-80 \mathrm{mg} / \mathrm{L}$ )

Group III = Highest hs-CRP group (hs-CRP= > 80-114 mg/L)

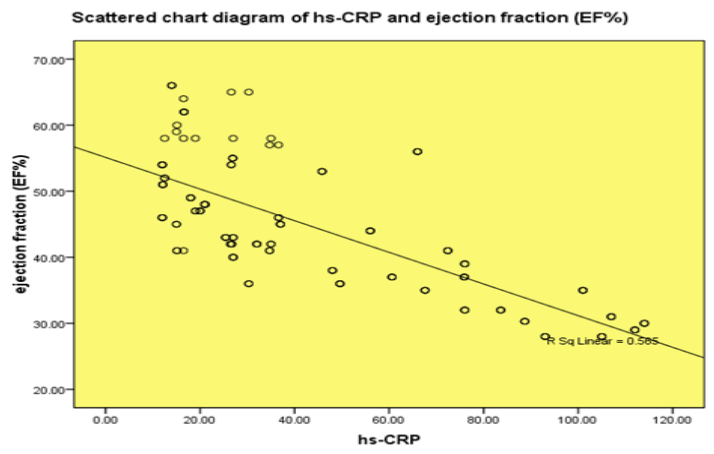

Figure 2: Association between hs-CRP level and ejection fraction / fractional shortening $(\%)$

\section{Discussion}

There is association between persistence of a marked inflammation as evidenced by raised hsCRP with a more severe impairment of ventricular function in patients with revascularised AMI. ${ }^{17}$

The present study was done to determine the association of hs-CRP with the severity of left ventricular systolic dysfunction in acute anterior
STEMI patients. We compared the left ventricular function by echocardiographic measurements of EF and FS in three groups based on lowest to highest hs- CRP level.

In this study the mean age of the patients of group III was significantly higher than group I $(\mathrm{p}=0.001)$ and group II $(p=0.034)$. No significant difference

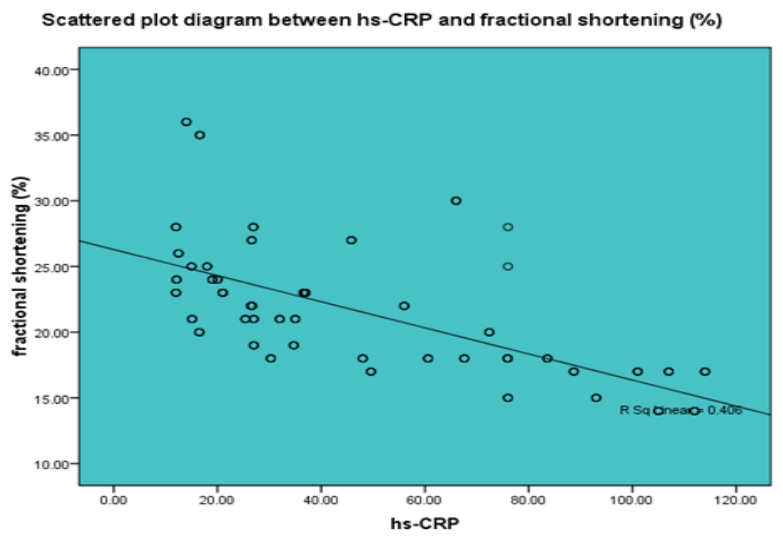

was observed between mean age of group I and group II. This finding was consistent with the finding of Schiele. ${ }^{16}$ They observed that patients with high hs-CRP were older than patients with low hs-CRP. ${ }^{16}$

It was found that patients with high hs-CRP had significantly more prevalence of diabetes mellitus (45.8\%, $p=0.031)$ and dyslipidemia (37.5\%, $p=0.033$ ) than patients with middle and lowest hsCRP level. However no significant difference was observed in the prevalence of smoking $(p=0.073)$, hypertension $(p=0.210)$, family history of premature $\mathrm{CAD}(p=0.492)$.

The mean $( \pm \mathrm{SD})$ EF of group III was significantly lower than group I ( $30.4 \pm 2.2$ Vs $49.6 \pm 7.7, p<0.001)$ and group II ( $30.4 \pm 2.2$ Vs $39.5 \pm 6.4, p<0.001)$. The same also for FS $(16.13 \pm 1.48$ Vs $23.96 \pm 4.23$ and $16.13 \pm 1.48$ Vs $19.56 \pm 4.19, p<0.001)$. Linear regression analysis shows progressive deterioration of EF and FS among the tertile. There were significant correlation between hs-CRP and EF $(\mathrm{r}=0.752, p<0.001)$ and with FS $(\mathrm{r}=0.637, p<0.001)$.

Severe and moderate reduction in EF was found significantly more in group III and II than group I $(p<0.001)$. This observation was consistent with the findings of Benedeket al. ${ }^{18}$ The ejection fraction was significantly lower in the patients with elevated 
levels of hs-CRP than lower hs-CRP level (52.91 \pm 4.03 Vs 49.04 $\pm 5.74, p=0.001)$ showing an inverse correlation with hs-CRP levels. ${ }^{18}$ Severe and moderate reduction in FS was found significantly more in group III and II than group I $(p<0.001)$.

Some other studies also showed that patients with high plasma CRP levels may be at risk for late LV dysfunction and remodeling and suggested that measuring plasma CRP levels may provide valuable information for long-term risk stratification after MI. ${ }^{13,16,19-21}$

The findings of the studies conducted by Smit et al and Brunetti et al and Basak and Akthtaruzzaman however did not support our observations. ${ }^{22-24}$

Smit et al found that higher levels of CRP were associated with a reinfarction or death within 1 year ( $p=0.006$ ), but not associated with left ventricular ejection fraction. ${ }^{22}$ The authors of the study did not explain the mechanisms why CRP does not predict left ventricular ejection fraction. The difference in finding between their study and the present study may be due to the fact that different timing of sample collection and the sample size of their study was almost three time to our study. Brunettiet al and Basak and Akthtaruzzaman did not found any correlation between CRP levels and ejection fraction. ${ }^{23-24}$ The inconsistency between the observation of their study and our study occurred because they measure serial CRP and peak CRP, and grouping pattern of hs-CRP are different.

\section{Conclusion}

The present study concludes that high level of hsCRP in patient of acute anterior STEMI patients is associated with left ventricular systolic dysfunction (moderate to severe reduction in ejection fraction and fractional shortening). So, hs- CRP can be a prognostic marker in acute anterior STEMI complicating left ventricular systolic dysfunction and early aggressive management can improve the short and long term prognosis of these patients.

\section{References}

1. Hellermann JP, Goraya TY, Jacobsen SJ, Weston SA, Reeder GS,Gersh BJ, Redfield MM, Rodeheffer RJ, Yawn BP, Roger VL.Incidence of heart failure after myocardial infarction: is it changing over time? American Journal of Epidemiology. 2003; 157:1101-1107.

2. Robin A. P. Weir,John J. V. McMurry, and Eric J. Velazquez.. Epidemiology of heart failure and left ventricular systolic dysfunction after acute myocardial infarction: prevalence, clinical characteristics, and prognostic importance. Am J Cardiol.2006; 97 [suppl]:13F-25F.

3. Velazquez EJ, Francis GS, Armstrong PW, Aylward PE, Diaz R, O'Connor CM, et al., An international perspective on heart failure and left ventricular systolic dysfunction complicating myocardial infarction: the VALLIANT Registry. European Heart Journal.2004; 25:1911-9.

4. Weir RA, McMurray JJ, Velazquez EJ. Epidemiology of heart failure and left ventricular systolic dysfunction after acute myocardial infarction: prevalence, clinical characteristics, and prognostic importance. American Journal of Cardiology.2006; 97:13-25.

5. Cleland JG, Torabi A, Khan NK. Epidemiology and Management of Heart Failure and Left Ventricular Systolic Dysfunction in the Aftermath of a Myocardial Infarction. Heart.2005; 91(Suppl 2): $17-13$.

6. Nian M, Lee P, Khaper N, Liu P. Inflammatory cytokines and post myocardial infarction remodeling. Circulation Research.2004; 94:154353.

7. Nunez J, Nunez E, Bodi V, Sanchis J, Minana G, Mainar L et al. Usefulness of the neutrophil to lymphocyte ratio in predicting long-term mortality in ST segment elevation myocardial infarction. American Journal of Cardiology.2008; 2008: 747752.

8. Gabay C, Kushner I.Acute-phase proteins and other systemic responses to inflammation. New England Journal of Medicine. 1999; 340:448-454.

9. Gabriel AS, Martinsson A, Wretlind B, Ahnve S.IL-6 levels in acute and post myocardial infarction: their relation to CRP levels, infarction size, left ventricular systolic function, and heart failure. European Journal of Internal Medicine.2004; 15: 523-528.

10. Kushner I, Broder ML, Karp D.Control of the acute phase response: serum C-reactive protein kinetics after acute myocardial infarction. Journal of Clinical Investigation. 1978; 61: 235-242.

11. Bursi F, Weston SA, Killian JM, Gabriel SE, Jacobsen SJ, Roger VL.C-reactive protein and heart failure after myocardial infarction in the community. American Journal of Medicine.2007; 120:616-622. 
12. Suleiman M, Aronson D, Reisner SA, Kapeliovich MR, Markiewicz W, Levy Y, Hammerman H. Admission C-reactive protein levels and 30-day mortality in patients with acute myocardial infarction. American Journal of Medicine. 2003; 115:695-701.

13. Suleiman M, Khatib R, Agmon Y, Mahamid R, Boulos M, Kapeliovich M, et al.Early inflammation and risk of long-term development of heart failure and mortality in survivors of acute myocardial infarction-predictive role of Creactive protein. Journal of American College of Cardiology.2006; 47: 962-8.

14. Anzai T, Yoshikawa T, Shiraki H, Asakura Y, Akaishi M, Mitamura H, Ogawa S. C-reactive protein as a predictor of infarct expansion and cardiac rupture after a first Q-wave acute myocardial infarction. Circulation.1997;96:778784.

15. Ohlmann P, Jaquemin L, Morel O, El Behlgiti R, Faure A, Michotey MO et al. Prognostic value of Creactive protein and cardiac troponin I in primary percutaneous interventions for ST-elevation myocardial infarction. American Heart Journal.2006; 152:116-127.

16. Schiele F, Meneveau N, Seronde MF, Chopard R, Descotes-Genon V, Dutheil J, et al. C-reactive protein improves risk prediction in patients with acute coronary syndromes. European Heart Journal .2010; 31:290-7.

17. Jako B, Benedek T, Toganel R, Bajka B, Barcan $\mathrm{A}$, Korodi $\mathrm{S}$ et al., Inflammation and Acute Coronary Syndromes - from biomarkers to novel imaging-based risk assessment tools. Experimental Clinical Cardiology. 2014; 20:58915898.

18. Benedek T, Jako B, Suciu Z, Benedek I. Correlations between severity of coronary atherosclerosis and persistent elevation of circulating C-reactive protein levels 30 days after an acute myocardial infarction. Revista Romana de Medicină de Laborator.2014; 22:49-61.

19. Morishima I, Sone T, Tsuboi H, Kondo J, Mukawa $\mathrm{H}$, Kamiya $\mathrm{H}$ et al, Plasma C-Reactive Protein Predicts Left Ventricular Remodeling and Function after a First Acute Anterior Wall Myocardial Infarction Treated with Coronary Angioplasty: Comparison with Brain Natriuretic Peptide. Clinical Cardiology. 2002; 25:112-116.

20. Harst PVD, Voors AA, Volbeda M, Buikema H, Veldhuisen DJV and Gilst WHV. Usefulness of Preoperative C-Reactive Protein and Soluble Intercellular Adhesion Molecule-1 Level for Predicting Future Cardiovascular Events After Coronary Artery Bypass Grafting. American Journal of Cardiology.2006; 97: 1697-1701.

21. Ferdous BA, SultanaN, Ahmed S, Khan EH, Atia F, Sultana S, Shahnaj A. Study of High Sensitive C-Reactive Protein in Ischemic Heart Disease. Bangladesh J Med Biochem,2013;6:11-13

22. Smit JJ, Ottervanger JP, Slingerland RJ, Kolkman JJ, Suryapranata H, Hoorntje JC, et al. Comparison of usefulness of C-reactive protein versus white blood cell count to predict outcome after primary percutaneous coronary intervention for ST elevation myocardial infarction. American Journal of Cardiology.2008; 101:446-51.

23. Brunetti ND, Troccoli R, Correale M, Pellegrino PL, Biase MD. C-reactive protein in patients with acute coronary syndrome: Correlation with diagnosis, myocardial damage, ejection fraction and angiographic findings. International Journal of Cardiology. 2006; 109:248- 256.

24. Basak SK, Akhtaruzzaman KM, Kundu AK, Dey SR, Uddin MF. Prognostic value of hs-CRP in acute STEMI in hospitalized patient. Medicine. 2012; 24:36-39.

*Correspondence: Aparna Rahman, Department of Cardiology, BIRDEM General Hospital, Dhaka, Bangladesh; e-mail: aparnadr28@gmail.com 